\title{
A dinâmica da notícia nas redes sociais na internet: uma categorização das ações participativas dos usuários no Twitter e no Facebook ${ }^{1}$
}

\section{Maíra de Cássia Evangelista de Sousa}

Doutoranda; Universidade Federal do Rio Grande do Sul jornalista.maira@gmail.com

\section{Resumo}

A dinâmica da notícia nas redes sociais na internet está relacionada à etapa de circulação a partir da forma de apresentação e do conteúdo das postagens e à recirculação a partir das ações participativas dos usuários. Neste artigo, o objetivo é apresentar uma proposta de categorização da recirculação no Twitter e no Facebook de acordo com as ações participativas dos usuários (filtro social e reverberação) e analisar como se dá essa recirculação nas redes sociais na internet. De caráter descritivo-analítico, o estudo combinou técnicas qualitativas e quantitativas. A análise foi realizada a partir de postagens publicadas em janeiro de 2013 nas contas do Twitter e do Facebook do portal jornalístico Estadão sobre o incêndio na Boate Kiss, ocorrido na cidade de Santa Maria (RS).

\section{Palavras-chave}

Notícia. Circulação. Redes sociais na internet.

\section{Introdução}

As redes sociais na internet (RSIs) facilitam a publicação, a discussão e o compartilhamento de conteúdo em um modelo de comunicação cada vez mais configurado pela participação. Nesse sentido, pesquisas apontam o aumento da prática de comentar e compartilhar artigos nas redes sociais na internet. Segundo o The State of the News Media

\footnotetext{
${ }^{1}$ Uma versão preliminar deste artigo foi apresentada no GT Estudos de Jornalismo do XXIII Encontro Anual da Compós, realizado em maio de 2014, em Belém (PA).
} 
20132, as pessoas acabam dando mais atenção às notícias indicadas por amigos ou familiares. O Brasil tem sido apontado como um dos países com maior participação nos sites de redes sociais, o que reflete também no consumo e na indicação de conteúdos de cunho noticioso. De acordo com o relatório do Reuters Institute Digital News Report 20133, 51\% dos brasileiros usam esses espaços como fonte de informação ${ }^{4}$. Nesse contexto, os sites de redes sociais já se apresentam entre os cinco principais meios de informação para $60 \%$ da amostra. Quando o assunto é participação, 44\% afirmam compartilhar ao menos uma notícia por semana por meio de algum site de rede social e 32\% fazem isso por e-mail.

Consideramos que nas redes sociais na internet, a notícia é construída e adaptada constantemente a partir das particularidades e das especificidades dos espaços no qual circula. Ao mesmo tempo, cada parte desta notícia é discutida, distribuída e enriquecida pelas ações participativas dos usuários. Nesse sentido, o conceito de dinâmica da notícia nas redes sociais na internet (LONGHI; SOUSA, 2012), neste trabalho, será referente ao movimento da notícia provocado pela interação dos actantes $^{5}$ da rede que a reconfiguram constantemente. Logo, envolve as organizações jornalísticas que as publicam, os usuários que comentam, replicam e algumas vezes à ressignificam e ainda, os sites de redes sociais e suas ferramentas 6 , que permitem as ações das organizações jornalísticas e dos usuários.

Entendendo que a dinâmica da notícia diz respeito à etapa de circulação a partir da forma de apresentação e do conteúdo das postagens e à recirculação por via das ações participativas dos usuários, definimos categorias de análise dessas três naturezas ${ }^{7}$ na dissertação de mestrado (SOUSA, 2013). Neste artigo, o objetivo é apresentar, especificamente, a proposta de categorização da recirculação das postagens a partir das ações participativas dos usuários (filtro social e reverberação) e analisar como se dá essa recirculação.

\footnotetext{
2 Relatório anual sobre a situação do Jornalismo nos Estados Unidos da América. In: The State of the news media. The Pew Research Center's Project for Excellence in Journalism. EUA, 18 mar. 2013. Disponível em <http://stateofthemedia.org/>. Acesso em: 19 abr. 2013.

3 A pesquisa foi realizada nos meses de janeiro e fevereiro de 2013 em nove países do mundo: Brasil, França, Alemanha, Dinamarca, Espanha, Itália, Japão, EUA e Reino Unido. In: Reuters Institute Digital News Report 2013. Tracking the Future of News. Reuters Institute for the Study of Journalism. Disponível em:

$<$ https://reutersinstitute.politics.ox.ac.uk/fileadmin/documents/Publications/Working_Papers/Digital_News_Report_2013.pd f>. Acesso em: 04 jul. 2013.

${ }^{4}$ Os dados se baseiam na população urbana do Brasil.

${ }^{5}$ Segundo a Teoria Ator-Rede, os actantes são considerados instâncias como usuários, ferramentas, tecnologias, códigos, dentre outros, que geram interações na rede (LATOUR, 2012).

${ }^{6} \mathrm{Na}$ perspectiva da Teoria Ator-Rede, os sites de redes sociais e todas as suas ferramentas que permitem a circulação e a reconfiguração da notícia no ciberespaço são considerados atores da rede, como exemplo: o botão compartilhar do Facebook ou o retweet do Twitter (LATOUR, 2012).

7 1. Circulação a partir da forma de apresentação das postagens; 2. Circulação a partir do conteúdo das postagens; 3. Recirculação a partir das ações participativas do usuário.
} 
O estudo de caráter descritivo-analítico combinou técnicas qualitativas e quantitativas. A análise foi realizada com base em 121 postagens do portal jornalístico Estadão no Twitter (Twitter.com/estadao) e 69 no Facebook (Facebook.com/estadao), publicadas entre os dias 27 e 31 de janeiro de 2013, sobre o incêndio ocorrido na Boate Kiss, na cidade de Santa Maria (RS). Na ocasião, 242 jovens morreram. 0 acontecimento foi considerado a quinta maior tragédia do Brasil, sendo a segunda maior em quantidade de mortos em incêndio, e é tido como a maior tragédia do Rio Grande do Sul. 0 caso ganhou grande repercussão no jornalismo brasileiro e internacional, ficando conhecido como a Tragédia de Santa Maria.

\section{Interseções entre jornalismo, redes sociais na internet e cultura participativa}

As redes sociais na internet são representações de atores e suas conexões (WASSERMAN; FAUST, 19948; DEGENNE; FORSÉ, $1999^{9}$ apud RECUERO, 2009a). Considerando a Teoria Ator-Rede (LATOUR, 2012), os atores podem ser humanos e não humanos, e, portanto, chamados de actantes.

Com a expansão da internet e o aumento do uso dos sites de redes sociais a partir dos anos 2000, as organizações noticiosas começam a também utilizar esses espaços, que têm se constituído na "alma do jornalismo na internet" (LONGHI; FLORES; WEBER, 2011, p. 19). Segundo Lara (2008), só oferecer informação não é mais o suficiente: "É preciso fornecer espaços de comunicação e socialização às audiências. [...] o objetivo está em captar novos públicos e a audiência em redes sociais". (LARA, 2008, documento eletrônico não paginado, tradução nossa) ${ }^{10}$.

As redes sociais na internet beneficiam os veículos jornalísticos, uma vez que favorecem: "1) melhora da identidade da marca, 2) fidelização dos leitores e 3) interatividade: beneficia os meios como plataforma de distribuição de seus conteúdos entre as redes, produzindo um efeito em cadeia, entre os membros da rede social e melhorando

\footnotetext{
8 WASSERMAN, Stanley; FAUST, Katherine. Social Network Analysis. Methods and Applications. Cambridge, UK: Cambridge University Press, 1994.

${ }^{9}$ DEGENNE, Alain; FORSÉ, Michel. Introducing Social Networks. London: Sage, 1999.

10 No original: "Como 'medios de comunicación social', han de proveer de espacios de comunicación y socialización a sus audiencias. [...] el reto estriba en captar nuevos públicos y convertir a sus audiencias en redes sociales". (LARA, 2008, documento eletrônico não paginado).
} 
sua repercussão". (ORIHUELA, 200911 apud VIVAR; CEBRIAN HERREROS, 2011, p. 163, tradução nossa) ${ }^{12}$. Desta forma, esses espaços são considerados como uma grande oportunidade para obter benefícios econômicos. Segundo Vivar e Cebrian Herreros (2011), as RSIs ampliam o público de qualquer organização de notícias:

Os links para os meios fornecidos pela própria empresa ou pelos usuários das redes sociais possibilitam um maior índice de penetração nos sites das mídias e um maior conhecimento da oferta dos meios de comunicação. Assim, e com este sistema, a imprensa escrita alcança um maior número de usuários únicos, aumentam os seus visitantes e o tempo médio de navegação do usuário no site da mídia. Através das redes sociais, qualquer mídia consegue mais informações sobre seu público (afinidades, dados interesse...). Assim, a imprensa informativa tem a possibilidade de segmentar sua audiência por grupos em função de seus interesses, aumentando assim, consideravelmente, a eficácia do impacto. (VIVAR; CEBRIAN HERREROS, 2011, p. 166, tradução nossa) ${ }^{13}$.

Nesse sentido, podemos considerá-las como verdadeiras vitrines para o conteúdo dos veículos jornalísticos. Ao analisar o atual cenário da indústria midiática, Primo (2013) destaca que a forma como a convergência vem sendo definida, tem agradado, sobretudo, à indústria, que tem retrabalhado a participação do público:

Quando se pensava que os grupos midiáticos não resistiriam à popularização das tecnologias digitais e à livre expressão em rede, o contra-ataque veio incorporando as próprias estratégias que lhes ameaçavam: user-generated contend, serviços de comentários, retuítes, enquetes, blogs e todo sabor de "redes sociais". É bem verdade que as indústrias midiáticas continuam em crise, mas elas continuam em luta e não baixam a guarda. A queda das vendagens de jornais, e até mesmo o fechamento de muitos periódicos impressos, não significa que os webjornais participativos tomaram esse lugar. 0 que se observa, pelo contrário, é o incremento progressivo das ações de recirculação com links para sites jornalísticos daquelas mesmas corporações jornalísticas. (PRIMO, 2013, p. 23).

As redes sociais na internet vêm para mostrar que as pessoas querem se comunicar e estar juntas, mesmo que em rede, visto que somos criaturas sociais (SANTAELLA; LEMOS,

\footnotetext{
11 ORIHUELA, José Luis. (2009). Redes sociales y educación. Disponível em: <http://www.ecuaderno.com/2009/03/10/redes-sociales-y-educacion>. Acesso em: 05 jan. 2012.

12 No original: “1) Mejorar su identidad de marca, 2) Fidelización de los lectores y 3) Interactividad: beneficia a los medios como plataforma de distribución de sus contenidos entre las redes, produciendo un efecto cadena entre los miembros de la red social y mejorando su repercusión". (ORIHUELA, 2009, op cit. apud VIVAR; CEBRIAN HERREROS, 2011, p. 164).

13 No original: "Los enlaces hacia los medios proporcionados por la propia empresa o por los usuarios de las redes sociales posibilitan un mayor índice de penetración en los sites de los medios y um mayor conocimiento de la oferta del medio de comunicación. Así y con este sistema, la prensa escrita alcanza un mayor número de usuarios únicos, aumentan sus visitan y crece el tiempo de navegación del usuario en la web del médio. A través de las redes sociales, cualquier medio consigue mayor información sobre su público (afinidades, datos de interés...). Así, la empresa informativa tiene la posibilidad de segmentar a su audiencia por grupos en función de sus intereses, con lo que la eficacia del impacto aumenta considerablemente". (VIVAR; CEBRIAN HERREROS, 2011, p. 166).
} 
2010). Nessa premissa, Shirky (2012) associa os seres humanos aos primatas, como chimpanzés e gorilas, para explicar que vamos mais além que eles na formação de grupos. Dessa forma, temos habilidades sociais formadas por grande inteligência individual, o que nos torna diferentes de outras criaturas.

Isso é importante para compreendermos as transformações que as tecnologias digitais têm causado à sociedade, uma vez que "Estamos vivendo em meio a um extraordinário aumento de nossas capacidades de compartilhar, de cooperar uns com os outros e de empreender ações coletivas, tudo isso fora da estrutura de instituições e organizações tradicionais". (SHIRKY, 2012, p. 23). Nesse contexto, diferentemente do que ocorria nos anos 1990, em que as pessoas não faziam questão de ter uma vida on-line, atualmente, elas não só o fazem como estão cada vez mais conectadas. Isso acontece porque antes as pessoas não estavam on-line, mas hoje "[...] computadores e telefones cada vez mais computadorizados foram amplamente adotados, toda a noção de ciberespaço está começando a desaparecer". (SHIRKY, 2011, p. 37). Assim, a ideia de um mundo real e de um mundo virtual desvinculados tem sido ofuscada cada vez mais. Logo, “[...] nossas ferramentas de mídia social não são uma alternativa para a vida real, são parte dela". (SHIRKY, 2011, p. 37).

Nesse contexto, a palavra participação ganha cada vez mais importância. Os sites de redes sociais favorecem a publicação, o comentário, o compartilhamento de informações e a produção coletiva de conteúdo, transformando o ecossistema midiático e o modelo padrão de comunicação do século XX existentes desde a institucionalização do jornalismo com produtores profissionais e consumidores amadores. A partir desse novo ecossistema midiático que abarca além das tradicionais organizações midiáticas, os usuários, agora considerados consumidores e produtores de conteúdo, é que surge o conceito de cultura participativa (JENKINS; FORD; GREEN, 2013; SHIRKY, 2011; JENKINS, 2009).

Antes do século XX, uma parte da cultura era participativa (encontros locais, eventos e performances), mas não precisava de uma expressão para defini-la, segundo Shirky (2011). Porém, a desagregação da vida social foi tamanha no século XXI, que agora temos o termo cultura participativa para descrever o atual momento, em que "[...] o simples ato de criar algo com outras pessoas em mente e então compartilhá-lo com elas representa, no mínimo, um eco daquele antigo modelo de cultura, agora em roupagem tecnológica" (SHIRKY, 2011, p. 23). Assim, a mídia é considerada por Shirky (2011, p. 25) um triatlo "[...] com três 
enfoques diferentes: as pessoas gostam de consumir, mas também gostam de produzir e de compartilhar". Porém, segundo o autor, até recentemente o único enfoque considerado era o consumo.

Para Jenkins, Ford e Green (2013), o conceito de cultura participativa evoluiu. Em 1992, quando cunhado por Jenkins, se referia à “[...] produção cultural e as interações sociais de comunidades de fãs, inicialmente buscando uma maneira de diferençar as atividades de fãs de outras formas de espectador". (JENKINS; FORD; GREEN, 2013, p. 02, tradução nossa) ${ }^{14}$. Atualmente, o termo diz respeito a "[...] uma diversidade de grupos que dispõe de produção e distribuição da mídia para servir a interesses coletivos. Vários estudiosos têm vinculado considerações do fandom ${ }^{15}$ em um discurso mais amplo sobre participação na e através da mídia". (JENKINS; FORD; GREEN, 2013, p. 02, tradução nossa) ${ }^{16}$.

Essa nova forma de circulação de conteúdo midiático que envolve o público consumidor, que se transforma também em produtor e filtro distribuidor de conteúdo, indica um modelo de cultura mais participativo, uma vez que as ferramentas permitem o envolvimento das pessoas, ao mesmo tempo em que elas querem compartilhar, assim, a união dessas novas práticas sociais e culturais relacionadas às novas tecnologias cria o que os autores denominaram de cultura em rede ${ }^{17}$ (JENKINS; FORD; GREEN, 2013).

As audiências vêm se remodelando. No entanto, as pessoas não estão compartilhando apenas por conta das possibilidades oferecidas agora pelas tecnologias, mas sim porque elas já faziam por meio do boca a boca. Para Jenkins, Ford e Green (2013), é preciso entender as práticas culturais que são anteriores a essas tecnologias e que evoluem com ela:

Enquanto as novas ferramentas têm proliferado a maneira pela qual as pessoas podem difundir materiais, fazer recomendações boca a boca e partilhar conteúdos midiáticos são impulsos que há muito tempo conduz a forma como as pessoas interagem umas com as outras. Talvez nada seja mais humano do que compartilhar histórias, seja pelo fogo ou pela "nuvem". (JENKINS; FORD; GREEN, 2013, p. 02-03, tradução nossa) ${ }^{18}$.

\footnotetext{
${ }^{14}$ No original: "The cultural production and social interactions of fan communities, initially seeking a way to differentiate the activities of fans from other forms of spectatorship" (JENKINS; FORD; GREEN, 2013, p. 02).

${ }^{15}$ Significa conjunto de fãs que se unem por conta de uma obra literária, televisiva, etc.

${ }^{16}$ No original: "A range of different groups deploying media production and distribution to serve their collective interests, as various scholars have linked considerations of fandom into a broader discourse about participation in and through media". (JENKINS; FORD; GREEN, 2013, p. 02).

${ }^{17}$ No original: "networked culture".

18 No original: "While new tools have proliferated the means by which people can circulate material, word-of-mouth recommendations and the sharing of media content are impulses that have long driven how people interact with each other. Perhaps nothing is more human than sharing stories, whether by fire or by "cloud"'. (JENKINS; FORD; GREEN, 2013, p. 2-3).
} 
No livro A conversação em rede, Recuero (2012, p. 17) considera que as práticas de compartilhamento de informação por boca a boca foram reconfiguradas, tornando-se mais públicas e mais coletivas: "essas conversações têm novos formatos e são constantemente adaptadas e negociadas para acontecer dentro das limitações, possibilidades e características da ferramenta".

\section{Da circulação à recirculação da notícia nas redes sociais na internet}

A circulação envolve os canais - os meios - onde a notícia circula após ser publicada, podendo ser, por exemplo: jornal impresso, rádio, televisão, portal jornalístico, smartphones e tablets ou até mesmo um site de rede social. Para Park (2008, p. 33), essa etapa é fundamental, pois um jornal em sua função “[...] não é simplesmente impresso. É publicado e lido. Se não for assim, não será um jornal. A luta pela existência no caso do jornal tem sido a luta pela circulação".

Neste contexto, podemos citar a definição de Machado (2008) para o sistema de circulação $^{19}$ no ciberjornalismo. 0 autor diferencia a distribuição com foco no consumo e a circulação cujo objetivo é a participação. Essa distinção é importante, segundo Machado, para explicar os sistemas de circulação jornalística a partir de cada período histórico. Ele considera que a distribuição: “[...] opera de forma centralizada, mantém uma hierarquia rígida entre os participantes e tem como objetivo principal a entrega das informações ao consumidor final”. (MACHADO, 2008, p. 08-09), enquanto a circulação "[...] funciona sem necessidade de uma hierarquia rígida, adota a descentralização como modelo padrão e tem como objetivo principal a disseminação das informações produzidas nestes diferentes centros". (MACHADO, 2008, p. 09).

Segundo o autor, esses sistemas de circulação podem ser estáticos ou dinâmicos. No primeiro caso, a informação vai até o consumidor, no segundo, é o público quem tem que buscá-la (MACHADO, 2008). 0 modelo de circulação estático predominou no ciberespaço entre 1995 e 1998. No entanto, esta etapa se dá cada vez mais a partir de sistemas dinâmicos, múltiplos e inteligentes. Desde 1999, tem-se “[...] o desenvolvimento de sistemas dinâmicos centralizados e descentralizados [...] e a multiplicação de sistemas ancorados em

${ }^{19}$ Segundo Machado (2008), a circulação é um dos sistemas menos discutidos na bibliografia especializada. 
tecnologias dinâmicas e descentralizadas desde 2004" (GILLMOR, 200420 apud MACHADO, 2008, p. 15). Contudo, os modelos podem coexistir na rede.

Para Jenkins, Ford e Green (2013), a principal característica da circulação de conteúdos midiáticos na atualidade é que eles se espalham tanto por ações da mídia como dos usuários: "De cima para baixo de baixo para cima, da base para o comercial". (JENKINS; FORD; GREEN, 2013, p. 01, tradução nossa) ${ }^{21}$. Os autores também diferenciam as definições de distribuição e de circulação. Segundo eles, existe uma confusão entre os dois termos. A distribuição ocorre quando as organizações medem, por exemplo, a quantidade de jornais vendidos. É quando há uma preocupação em fazer com que o público de massa consuma aquele determinado produto já acabado, seguindo a lógica de distribuição, "Essas definições de "circulação" estão realmente falando sobre distribuição, onde o movimento do conteúdo midiático é largamente - ou totalmente - controlado pelos interesses comerciais de produção e venda". (JENKINS; FORD; GREEN, 2013, p. 01, tradução nossa) ${ }^{22}$. No atual modelo híbrido emergente de circulação, há "[...] uma mistura de forças top-down e bottomup que determina como o material é compartilhado por e entre culturas de formas mais participativas (e mais confusas)". (JENKINS; FORD; GREEN, 2013, p. 01, tradução nossa) ${ }^{23}$. Neste segundo caso, na circulação, o produto pode sofrer reconfigurações pelos usuários, indicando um modelo mais participativo:

Que vê o público não como simples consumidor de mensagens préconstruídas, mas como pessoas que estão moldando, compartilhando, reformulando e remixando o conteúdo da mídia de maneira que não possa ter sido anteriormente imaginado. E eles estão fazendo isso não como indivíduos isolados, mas dentro de comunidades e redes maiores, que os permite espalhar o conteúdo bem além de sua proximidade geográfica imediata. (JENKINS; FORD; GREEN, 2013, p. 02, tradução nossa) ${ }^{24}$.

Para descrever as atuais formas de circulação, os autores utilizam os termos spread, spreadable e spreadability, os quais poderíamos traduzir como espalhar, espalhável e espalhabilidade, respectivamente. A expressão alude a essa possibilidade, técnica e cultural, que o público tem de compartilhar informações:

${ }^{20}$ GILLMOR, Dan. We the media: grassroots journalism by the people, for the people. O’Reilly, Sebatopol, Canada, 2004.

${ }^{21}$ No original: "From top down to bottom up, from grassroots to commercial". (JENKINS; FORD; GREEN, 2013, p. 01).

22 No original: "Those definitions of "circulation" are really talking about distribution, where the movement of media content is largely - or totally - controlled by the commercial interests producing and selling it" (JENKINS; FORD; GREEN, 2013, p. 01).

${ }^{23}$ No original: "A mix of top-down and bottom-up forces determine how material is shared across and among cultures in far more participatory (and messier) ways". (JENKINS; FORD; GREEN, 2013, p. 01).

${ }^{24}$ No original: "Which sees the public not as simply consumers of preconstructed messages but as people who are shaping, sharing, reframing, and remixing media content in ways which might not have been previously imagined. And they are doing so not as isolated individuals but within larger communities and networks, which allow them to spread content well beyond their immediate geographic proximity". (JENKINS; FORD; GREEN, 2013, p. 02). 


\begin{abstract}
Mesmo se nenhum comentário adicional for anexado, no entanto, apenas receber uma história ou um vídeo de alguém traz uma série de novos significados potenciais ao texto. Enquanto as pessoas ouvem, leem ou veem o conteúdo compartilhado, elas não pensam - normalmente nem mesmo primariamente - sobre o que os produtores queriam dizer, mas sobre o que a pessoa que compartilhou o conteúdo estava tentando comunicar. (JENKINS; FORD; GREEN, 2013, p. 13, tradução nossa) ${ }^{25}$.
\end{abstract}

Neste sentido, destacamos o conceito de cultura em rede proposto pelos autores, visto que a conversação sobre as notícias publicadas já ocorre desde a época dos boletins. Prova disso é esta frase de Park da primeira metade do século passado: "A primeira reação típica de um indivíduo à notícia é provavelmente o desejo de repeti-la para alguém. Isso cria a conversação, provoca maiores comentários e talvez comece uma discussão". (PARK, 2008, p. 60). Desta forma, se antes comentávamos boca a boca sobre uma notícia lida, ouvida ou assistida, as tecnologias digitais potencializam e reconfiguram esta prática. Assim, além de comentar uma determinada publicação de uma organização jornalística, as pessoas agora podem encaminhá-la aos seus amigos, com outras informações ou a sua própria opinião sobre um determinado acontecimento.

$\mathrm{O}$ ato de comentar e replicar informações nas redes é chamado de recirculação por Zago $(2011)^{26}$, sendo uma subetapa da circulação, que ocorre após o consumo, quando o usuário utiliza "espaços sociais diversos da internet (como sites de relacionamento, blogs, microblogs, dentre outros) e contribuindo para divulgar o link para a notícia, recontar com suas palavras o acontecimento ou manifestar sua opinião sobre o ocorrido (ZAGO, 2011, p. 63). Assim, segundo a autora, uma informação pode recircular “[...] a partir da apropriação e ressignificação de seu conteúdo nas mãos dos interagentes". (ZAGO, 2013, p. 230). No Twitter, por exemplo, um usuário pode retweetar uma informação ou mesmo fazer menção a um determinado tweet, enquanto que no Facebook é possível curtir e compartilhar a informação e fazer comentários. Nos casos de replicação, também é possível adicionar mais informações:

Da mesma forma como os veículos se apropriam desses espaços para distribuir notícias, também os interagentes podem utilizar sites de redes sociais para comentar - expressar opinião, criticar, reagir com humor em determinados acontecimentos jornalísticos - e para filtrar - postar

\footnotetext{
${ }^{25}$ No original: "Even if no additional commentary is appended, however, just receiving a story or video from someone else imbues a range of new potential meanings in a text. As people listen, read, or view shared content, they think not only - often, not even primarily - about what the producers might have meant but about what the person who shared it was trying to communicate". (JENKINS; FORD; GREEN, 2013, p. 13).

${ }^{26} \mathrm{~A}$ autora trabalha com o termo recirculação jornalística voltada para o Twitter.
} 
pequenas notas, links ou manchetes - notícias, vindo a contribuir para uma recirculação jornalística. (ZAGO, 2013, p. 213).

As ações de recirculação de informações nas redes são discutidas por vários autores, dentre eles, Stelter (2008), que denominou filtro social a prática de compartilhar artigos. Segundo o autor, o filtro social substitui as conversas boca a boca, uma vez que as pessoas consomem as informações e depois filtram e repassam para seus amigos, seja a partir de emails ou das próprias redes sociais na internet.

De acordo com Recuero (2009b), há duas relações entre jornalismo e redes sociais na internet que são diretamente ligadas à circulação, ou melhor, à recirculação de informações, ou seja, os usuários podem atuar tanto como filtros de informação quanto como reverberadores de informação.

No primeiro caso, a filtragem de informações ocorre quando os usuários coletam e republicam as informações de veículos jornalísticos ou mesmo do site de rede social e a republicam, esta sendo a forma mais comum de difusão de informações. No caso ao repassar a informação postada por um perfil de uma organização jornalística, os usuários estão dando credibilidade a esse veículo (RECUERO, 2009b).

O segundo caso, reverberação, caracteriza-se quando os sites das redes sociais são usados como espaços de discussão de informações, a partir de menções ou comentários (RECUERO, 2009b). Segundo a autora,

Está relacionada também com o fato de que as redes sociais são espaços de circulação de informações. Com isso, tornam-se também espaços de discussão dessas informações, onde as notícias, por exemplo, são reverberadas [...] Com isso, a ferramenta permite não apenas a difusão das informações, mas igualmente o debate em cima das mesmas. (RECUERO, 2009b, p. 9-10).

A partir das definições de Recuero (2009b), Zago (2011) categorizou as ações participativas de recirculação de informação no Twitter como filtro e comentário: o primeiro acontece quando o usuário reproduz o conteúdo do veículo, com ou sem alterações, e/ou direciona o leitor para a matéria original por meio de links, e o segundo é quando há uma manifestação pública de opinião sobre um acontecimento ou sobre a situação do mesmo.

Neste artigo, vamos concentrar a nossa análise na recirculação, ou seja, nessa subetapa da circulação em que a informação é redistribuída a partir das ações participativas dos usuários das redes. 


\section{Proposta de categorização da recirculação a partir das ações participativas dos usuários}

Na tentativa de categorizar as ações participativas dos usuários nas redes sociais na internet usamos as definições de filtro social (STELTER, 2008) e de filtro e reverberação (RECUERO, 2009b). Contudo, a participação dos atores da rede foi apenas classificada em filtro social e reverberação. A definição está no quadro a seguir, no qual apresentamos a definição das categorias de análise propostas em relação à recirculação da notícia nas redes sociais na internet a partir das ações participativas dos usuários:

Quadro 1 - Categorias de recirculação a partir de ações participativas dos usuários

\begin{tabular}{l|l} 
Filtro social & $\begin{array}{l}\text { Ocorre quando uma postagem do perfil de uma organização jornalística em algum } \\
\text { site de rede social é indicada e/ou replicada por um usuário aos seus seguidores. } \\
\text { Nesse caso, a publicação recircula nas redes sociais na internet. Por exemplo, um } \\
\text { retweet no Twitter ou um curtir e/ou compartilhar no Facebook. }\end{array}$ \\
\hline Reverberação & $\begin{array}{l}\text { Ocorre quando uma postagem do perfil de uma organização jornalística em algum } \\
\text { site de rede social é comentada pelos usuários das redes sociais na internet. Por } \\
\text { exemplo, temos o responder no Twitter e o próprio comentar no Facebook. }\end{array}$
\end{tabular}

Fonte: elaborado pela autora.

\subsection{Como se dá a recirculação das postagens nos perfis jornalísticos do Twitter e do Facebook?}

Antes de iniciarmos a discussão sobre a recirculação a partir das ações participativas dos usuários, vale destacarmos as particularidades e especificidades dos dois sites de redes sociais em estudo, em relação às possibilidade de interação. 0 Twitter permite retweetar $\mathrm{e}$ responder os tweets e o Facebook possibilita curtir, comentar e compartilhar as postagens ${ }^{27}$.

No Twitter.com/estadao, a principal ação participativa realizada pelos usuários foi o filtro social, no caso, o retweet. Em todas as publicações o retweetar foi superior ao responder. Em alguns tweets, como podemos ver no gráfico 1, a quantidade de ações atividades referentes às duas ações chegou a ser próxima (quando a mensagem recebia poucas replicações), entretanto, o número de retweets foi superior em todos os casos.

${ }^{27}$ Essas eram as ações permitidas durante o período em que ocorreu esta análise: junho e julho de 2013. 
Gráfico 1 - Quantidade de ações participativas por postagem no Twitter.com/estadao

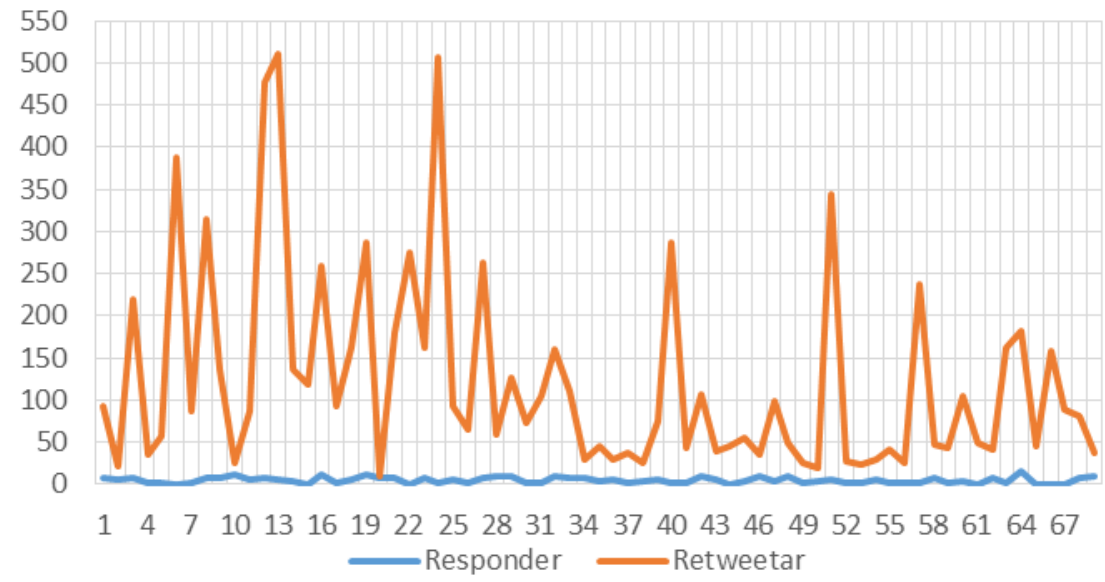

Fonte: elaborado pela autora.

Os tweets do dia da ocorrência do incêndio são os que alcançaram maior quantidade de ações participativas, no caso, o retweet, categorizado como filtro social. Contudo, a postagem da categoria reverberação com maior número de ações foi do dia subsequente (dia 28 de janeiro de 2013), que informava a proibição de funcionamento de todas as boates da cidade de Americana. Ao todo, esse tweet recebeu 16 menções.

Em decorrência da grande quantidade de tweets, optamos por focar apenas nos 12 com maior quantidade de ações participativas, correspondentes a $10 \%$ do total das postagens analisadas. Dessas publicações, nove são do domingo, dia 27 de janeiro, e apenas três da segunda-feira, dia 28. A quantidade de ações participativas por postagem variou entre 238 e 510 retweets. Para um melhor entendimento, numeramos as postagens na Figura 1 a partir da ordem de publicação: 
Figura 1 - Postagens com maior quantidade de ações participativas no Twitter.com/estadao

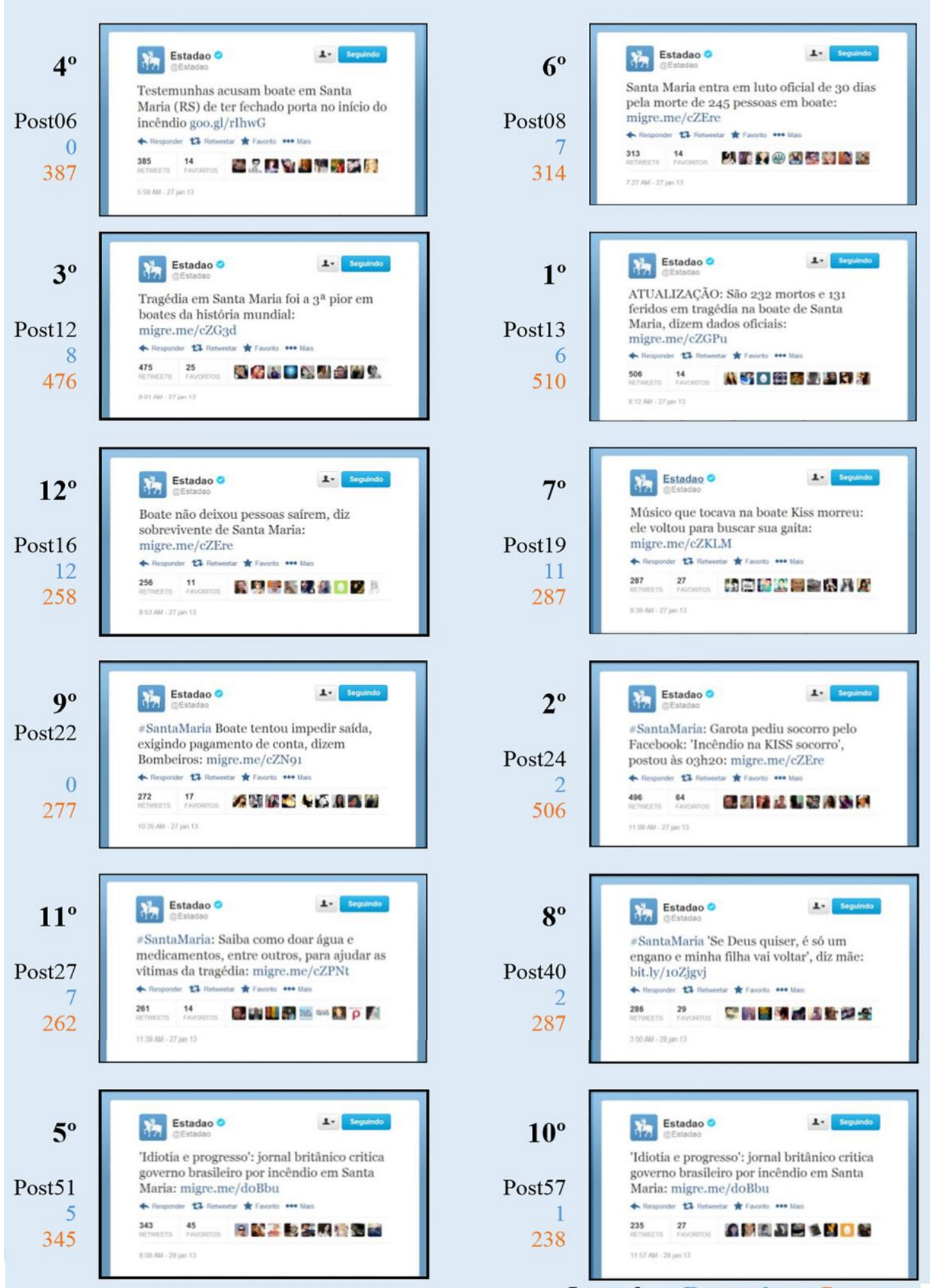

Fonte: elaborada pela autora.

Legenda: Responder Retweetar 
No Facebook.com/estadao, as principais ações participativas realizadas pelos usuários são relacionadas à categoria filtro social - o curtir e o compartilhar. Apesar de termos registrado um caso com 20 mil compartilhamentos, nos demais quem se sobressai é o curtir, seguido do compartilhar e do comentar. Ao todo, das 69 postagens, 51 receberam mais curtidas, 14 mais compartilhamentos e quatro mais comentários. A quantidade de ações participativas por postagem no Facebook.com/estadao pode ser mais facilmente compreendida no Gráfico 2, abaixo:

Gráfico 2 - Quantidade de ações participativas por postagem no Facebook.com/estadao

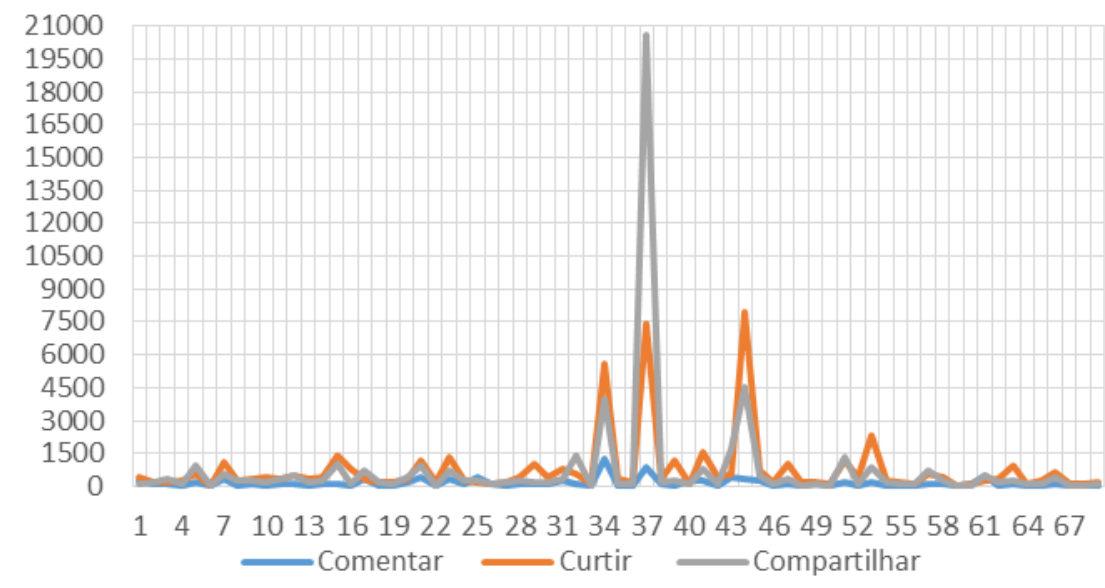

Fonte: elaborado pela autora.

No período de coleta de dados, selecionamos as seis publicações com o maior número de ações participativas (correspondentes a 10\% do total das postagens). Se observarmos a Figura 2, elas equivalem àquelas com mais de 1.500 dessas ações. Das seis publicações, cinco são do dia 28, segunda-feira, e apenas uma do dia 29, terça-feira. Para uma melhor organização das postagens, elas foram numeradas a partir da ordem de publicação de cada uma.

Entre os destaques, podemos mencionar a postagem 44 sobre a marcha silenciosa ocorrida em Santa Maria na segunda-feira à noite, dia 28, registrando o maior número de curtidas, quase oito mil (ver post44, Figura 2). Apesar das publicações receberem poucos comentários, a de número 34, referente à crítica recebida pelo governo brasileiro de um jornal britânico, foi a mais comentada de todas, com mais de 1.200 comentários (ver post34, 
Figura 2). Ainda assim, a mensagem 37, a primeira publicação solicitando indicações de baladas inseguras, foi a com maior quantidade de ações participativas na rede. Ela foi a mais compartilhada, com 20.558 replicações. Vale mencionar a grande quantidade de ações recebidas por esta mensagem, pois ela também ficou em segundo lugar em número de curtidas e de comentários.

Figura 2 - Postagens com maior quantidade de ações participativas no Facebook.com/estadao Post34

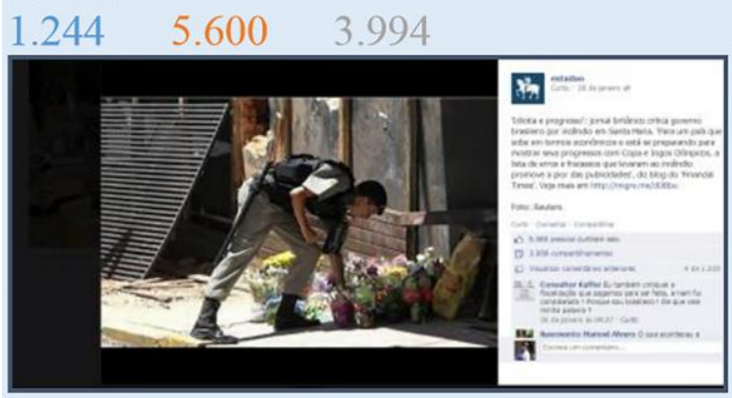
Post 37
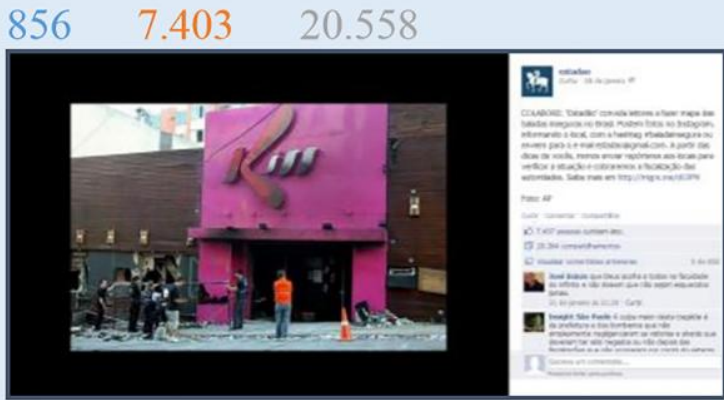

Post41

Post43

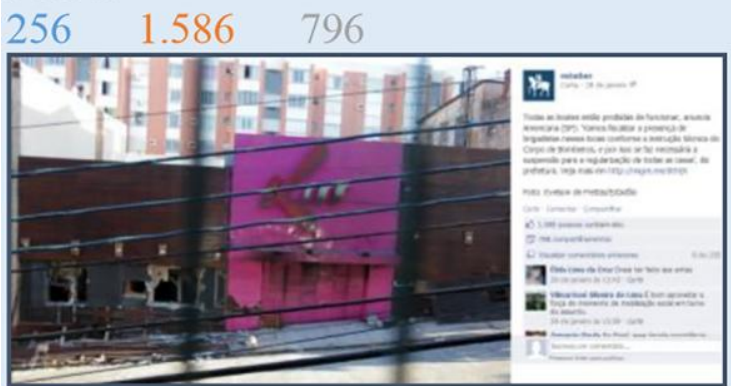

$\begin{array}{lll}382 & 593 \quad 1739\end{array}$

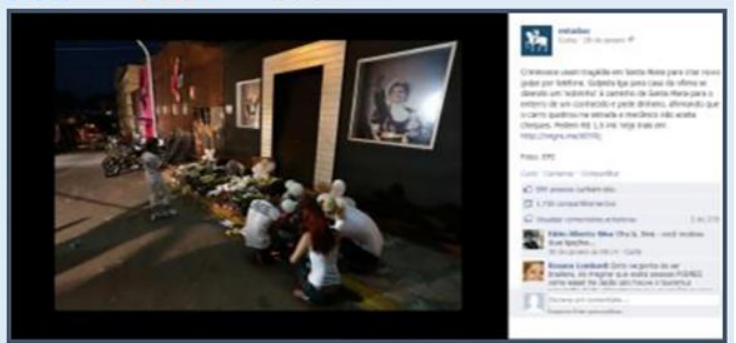

\section{Post44}

Post53

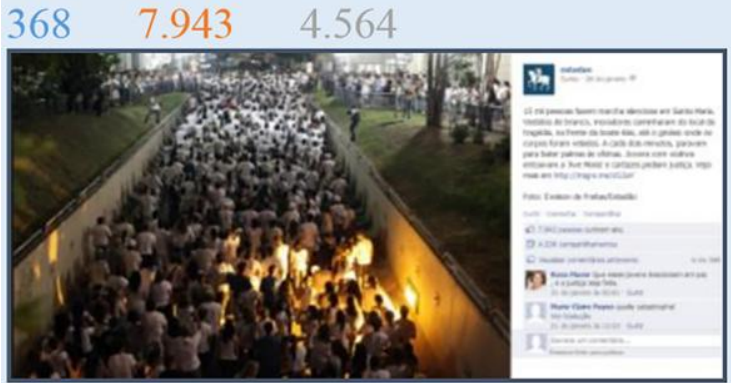

227

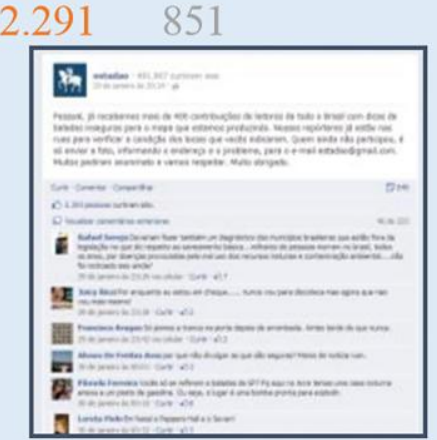

Legenda:

Fonte: elaborada pela autora. 
Nos dois sites de rede social em estudo predominaram as ações de filtro social, o que mostra o desejo dos usuários de se comunicar, muito mais do que expressar opinião, confirmando a afirmação de Jenkins, Ford e Green (2013).

No geral, constatamos algumas divergências entre os assuntos que mais recircularam. Em relação ao filtro social no Twitter, as mensagens que ganharam mais retweets diziam respeito à confirmação do número de mortos na tragédia (ver Post13, Figura 1), a menina que postou um pedido de socorro no Facebook (ver Post24, Figura 1) e a informação que classifica o caso de Santa Maria como o terceiro pior em questão de incêndio em boates (ver Post12, Figura 1). Já no Facebook, chamamos atenção para a mensagem que pedia a colaboração dos usuários (ver Post37 na Figura 2), essa postagem recebeu mais de 20 mil compartilhamentos, o que pode demonstrar uma vontade da parte do público de participar, seja como fonte ou como indicador da mensagem para que outras pessoas atuem como fontes. Essa publicação também ficou em segundo lugar em quantidade de comentários e de curtidas.

A reverberação apresentou uma maior quantidade de ações no Facebook, talvez isso aconteça por conta da natureza desta rede social na internet, a qual permite que os comentários apareçam de forma mais organizada. Nesse sentido, considerando a Teoria Ator-Rede (LATOUR, 2012), as ferramentas podem influenciar na forma como ocorrem determinadas práticas, no caso, a explicitação da opinião, em cada um desses espaços. Apesar das respostas e comentários aparecerem para quem tem conexão com o usuário, no Facebook os comentários aparecem logo abaixo da mensagem, enquanto no Twitter é preciso clicar no botão "ver conversa" para ter acesso ao diálogo. Dado esse fato, o número de comentários e menções nas duas redes sociais foi completamente desproporcional. No Twitter a mensagem que atingiu maior número de menções era referente à cidade de Americana. Ao todo foram 16 respostas. No Facebook, porém, a postagem sobre a crítica que o governo brasileiro recebeu de um jornal britânico conseguiu 1244 comentários. As duas publicações são da segunda-feira, dia 28.

Verificamos ainda outra relação, devido às particularidades e especificidades desses espaços. Em geral, a quantidade de ações participativas no Facebook por mensagem é maior do que no Twitter. A média das postagens com maior quantidade de ações participativas no Twitter foi superior a 115, enquanto que no Facebook, 1500. Contudo, no domingo, dia 27, principalmente durante a tarde, observamos que as ações participativas dos usuários por 
mensagem foi menor no Facebook. Provavelmente por conta da grande quantidade de postagens. Diferente da segunda-feira, por exemplo, em que ocorreram muitas publicações, mas de forma mais distribuída, sendo o dia em que as publicações do Facebook alcançaram o maior número de ações de filtro social e reverberação. Nesse sentido, pensamos que isso se deu por conta dos filtros da própria ferramenta, visto que na medida em que são postadas várias informações em um pequeno espaço de tempo nem todas aparecem no feed de notícias dos usuários, diferente do Twitter.

Assim, consideramos que no Facebook há dois filtros. 0 primeiro é feito por conta dos algoritmos, pois a partir da contagem das interações entre os perfis o próprio site de rede social passa a atuar como mediador à medida que determina o que será visualizado por cada usuário, o que podemos chamar de "filtro técnico". Nesse sentido, é importante levar em conta a Teoria Ator-Rede (LATOUR, 2012), uma vez que as ferramentas dos sites de redes sociais também estão participando da ação. 0 segundo filtro ocorre partir da indicação dos usuários da rede, nesse caso, seria o filtro que estamos analisando: o filtro social. Acreditamos que, por isso, o dia em que as publicações do Twitter atingiram maior alcance foi o domingo, e as do Facebook, a segunda-feira. Percebemos assim que, mesmo se tratando de sites de redes sociais de um mesmo veículo jornalístico, há diferenças.

Confirmamos que as redes sociais na internet favorecem a reconfiguração de algumas práticas que surgem com a própria notícia. 0 antigo boca a boca e as conversações são um exemplo disso, visto que agora se dão pelo ato de replicar ou comentar uma publicação. No entanto, a diferença é que as indicações de conteúdo e as conversações passaram a acontecer pelo mesmo canal por onde o público recebe as informações: os sites de redes sociais.

O filtro social que é o ato de recomendar, indicar uma notícia a um amigo, um familiar ou mesmo às pessoas da rede com quem se tem conexões, surge com a própria notícia (PARK, 2008). Assim, é fundamental a compreensão de que o tradicional boca a boca é remodelado, no Twitter e no Facebook especificamente, a partir do retweetar, do curtir e do compartilhar. Nesse sentido, consideramos o filtro social como uma reformulação de uma prática que é comum ao ser humano, o compartilhamento de histórias (JENKINS; FORD; GREEN, 2013). Ressaltamos que, no Twitter, a mensagem é simplesmente replicada, enquanto que no Facebook há a possibilidade de indicar que você gostou e/ou concorda com a publicação, o curtir, e há também a possibilidade de adicionar algum comentário ao 
compartilhamento, mesmo que em quase metade dos casos, os usuários apenas repliquem a informação 28 .

A reverberação também está relacionada ao boca a boca e às conversações. É mais uma prática reconfigurada por esses espaços. No caso das redes sociais na internet, elas favorecem que as pessoas apresentem suas opiniões e debatam publicamente. Optamos pelo termo reverberação utilizado por Recuero (2009b), visto que ao mencionar ou comentar uma publicação além dela gerar uma discussão, esse ato aparece para os seguidores/amigos de quem publicou, ou seja, a publicação atua também como um filtro.

\section{Considerações finais}

Ainda que possa haver outras formas de circulação e recirculação da notícia nas redes sociais na internet, para este trabalho nos detivemos nas ações de circulação a partir dos perfis de sites de rede social.

A tragédia em Santa Maria é um acontecimento que pode ser configurado como excepcional, trágico e impactante, devido às características e proporções que teve, causando grande repercussão nacional e internacional. Assim, os resultados desta pesquisa se aplicam a acontecimentos dessa natureza. Talvez em outros tipos de acontecimentos, a recirculação da notícia pode se dar de forma diferente, configurando-se em um desafio para novas investigações.

Verificamos que esses espaços participativos enriquecem e aumentam o alcance da notícia, ao mesmo tempo em que modificam o modo de produzir, distribuir e consumir a informação jornalística. Independente do site de rede social utilizado, é inegável que o uso de espaços participativos pelo jornalismo é algo que tende a crescer cada vez mais, pois comunicar, compartilhar e estar junto faz parte do ser humano, assim, o jornalismo só tem a ganhar. Dessa forma, esperamos que esse estudo contribua para outras investigações sobre a recirculação da notícia nas redes sociais na internet.

\footnotetext{
28 Em um estudo realizado em 2012 sobre as ações participativas dos usuários no Facebook, observamos que aproximadamente $50 \%$ dos compartilhamentos, são apenas replicações, pois os usuários não adicionaram comentário algum ao mesmo (SOUSA, 2012).
} 


\section{Referências}

JENKINS, Henry. Cultura da convergência. 2. ed. São Paulo: Aleph, 2009.

JENKINS, Henry; FORD, Sam; GREEN, Joshua. Introduction to Spreadable Media. (2013).

Disponível em <http://www.fromthesquare.org/?p=4259>. Acesso em: 05 fev. 2013.

LARA, Tíscar. La nueva esfera pública: los medios de comunicación como redes sociales. (2008). Disponível em:

<http://sociedadinformacion.fundacion.telefonica.com/telos/articulocuaderno.asp@idartic ulo=9\&rev=76.htm $>$. Acesso em: 19 abr. 2013.

LATOUR, Bruno. Reagregando o social: uma introdução à teoria do Ator-Rede. Salvador: Edufba, 2012; Bauru: Edusc, 2012.

LONGHI, Raquel Ritter; SOUSA, Maíra. A dinâmica da notícia na internet: organizações jornalísticas e atores da rede. Contemporanea, Salvador, v. 10, n. 3, p. 511-529, 2012.

LONGHI, Raquel Ritter, FLORES, Ana Marta; WEBER, Carolina. Os webjornais querem ser rede social? In. SOSTER, Demétrio de Azeredo; LIMA JÚNIOR; Walter Teixeira (orgs.). Jornalismo digital: audiovisual, convergência e colaboração. Santa Cruz do Sul: EdUnisc, 2011. p. 18-42.

MACHADO, Elias. Sistemas de circulação no ciberjornalismo. (2008). Disponível em: $<$ http://www.pos.eco.ufrj.br/ojs-

2.2.2/index.php?journal=revista\&page $=$ article\&op=viewFile\&path $\% 5 B \% 5 \mathrm{D}=122 \&$ path $\% 5 \mathrm{~B}$ $\% 5 \mathrm{D}=124>$. Acesso em: 03 out. 2012.

PARK, Robert. A história natural do jornal. In: BERGER, Christa; MAROCCO, Beatriz (orgs.). A era glacial do jornalismo: teorias sociais da imprensa. Porto Alegre: Sulina, 2008. v. 2, p. 33-50.

PRIMO, Alex. Interações mediadas e remediadas: controvérsias entre as utopias da cibercultura e a grande indústria midiática. In: PRIMO, Alex (org.). Interações em rede. Porto Alegra: Sulina, 2013. p. 13-32.

RECUERO, Raquel. A conversação em rede: comunicação mediada pelo computador e redes sociais na internet. Porto Alegre: Sulina, 2012.

RECUERO, Raquel. Redes sociais na internet. Porto Alegre: Sulina, 2009a.

RECUERO, Raquel. Redes Sociais na Internet, Difusão de Informação e Jornalismo: Elementos para discussão. In: SOSTER, Demétrio de Azeredo; FIRMINO, Fernando. (Org.). Metamorfoses jornalísticas 2: a reconfiguração da forma. Santa Cruz do Sul: UNISC, 2009b, p. 37-55.

SANTAELLA, Lucia; LEMOS, Renata. Redes sociais digitais: a cognição conectiva do Twitter. São Paulo: Paulus, 2010. 
SHIRKY, Clay. Lá vem todo mundo: o poder de organizar sem organizações. Rio de janeiro: Zahar, 2012.

SHIRKY, Clay. A cultura da participação: criatividade e generosidade no mundo conectado. Rio de Janeiro: Zahar, 2011.

SOUSA, Maíra. A circulação da notícia em tempos de redes sociais: convergência, participação, filtros e economia da atenção. In: ENCONTRO NACIONAL DE PESQUISADORES EM JORNALISMO - SBPJOR, 10., 2012, Curitiba, Anais... Curitiba, Brasil.

SOUSA, Maíra. A dinâmica da notícia nas redes sociais na internet. Dissertação (Mestrado em Jornalismo) - Programa de Pós-graduação em Jornalismo, Universidade Federal de Santa Catarina, Florianópolis, 2013.

STELTER, Brian. Finding Political News Online, the Young Pass It On. The New York Times, 27 mar. 2008. Disponível em:

<http://www.nytimes.com/2008/03/27/us/politics/27voters.html>. Acesso em: 19 out. 2012.

VIVAR, Jesús Miguel Flores; CEBRIAN HERREROS, Mariano. Redes sociales, folksonomías e inteligencia colectiva en el desarrollo de la información periodística en internet (2011). In: VERÓN LASSA, José Juan; SABÉS TURMO, Fernando (Orgs.). La investigación en periodismo digital: algunos trabajosdesde el ámbito universitário. Disponível em: <http://pt.scribd.com/doc/50442310/La-investigacion-en-periodismo-digital-Algunostrabajos-desde-el-ambito-universitario>. Acesso em: 12 ago. 2012

ZAGO, Gabriela. Da circulação à recirculação jornalística: filtro e comentário de notícias por interagentes no Twitter. In: PRIMO, Alex (Org.). Interações em rede. Porto Alegra: Sulina, 2013, p. 211-321.

ZAGO, Gabriela. Recirculação jornalística no Twitter: filtro e comentário de notícias por interagentes como uma forma de potencialização da circulação. Dissertação (Mestrado em Comunicação e Informação). Porto Alegre: PPGCOM/UFRGS, 2011.

\title{
The news dynamics on social networking sites: a categorization of participatory actions of users on Twitter and Facebook.
}

\begin{abstract}
The news dynamics on social networking websites is related to the circulation stage, from the form of presentation and from the content of the posts, as well as to the recirculation from the participatory actions of users. The objective of this article is to
\end{abstract}


propose a categorization of recirculation on Twitter and Facebook according to the participatory actions of the users (by social filter and reverb) and to analyze how this recirculation is configured in social networking websites. As a descriptiveanalytic study, the research combines qualitative and quantitative techniques. The analysis was conducted from posts about the fire on the Kiss Nightclub, in Santa Maria (Rio Grande do Sul), published in January, 2013, on Twitter and Facebook accounts of the journalistic portal Estadão.

\section{Keywords}

News. Circulation. Social networks sites.

Recebido em 01/07/2014

Aceito em: 05/11/2014 